\title{
Impact of Volunteering on Cognitive Decline of the Elderly
}

\author{
Sumedha Gupta*
}

January 24,2018

\begin{abstract}
Cognitive decline among the elderly imposes a large welfare and health care cost on the individual as well as society. Little however is known about factors that can mitigate cognitive decline. Using seven waves of the Health and Retirement Study and a fixed effects - instrumental variable methodology, this study estimates the effects of volunteering on old age cognitive decline. Although cognitive decline is an inevitable aspect of aging, our results suggest that volunteering participation significantly forestalls its progress among individuals aged 60 years and older.
\end{abstract}

*Department of Economics, Indiana University-Purdue University Indianapolis, 523 Cavanaugh Hall, Indianapolis, IN 46202-5147. sugupta@iupui.edu.

Keywords: cognitive ability, pro-social engagement, volunteering, selectivity, health. JEL codes: I12, J14, E32, N33, N13, C41.

Version September 2017. Special thanks to Mark Wilhelm, Anne Royalty, Vidhura Tennekoon, Richard Steinberg, Gopi Shah Gowda, the Editor and two anonymous referees for their valuable suggestions and comments.

This is the author's manuscript of the article published in final edited form as:

Gupta, S. (2018). Impact of volunteering on cognitive decline of the elderly. The Journal of the Economics of Ageing, 12, 46-60. https://doi.org/10.1016/j.jeoa.2018.01.002 


\section{Introduction}

Cognitive decline among the elderly, an inevitable component of aging, imposes a large personal and public health care cost. Recent estimates show that cognitive decline, along with its co-morbidities of dementia and Alzheimer's disease, affects $14.7 \%$ of the US population above age 70 in 2010, with an associated health care cost between $\$ 157$ and $\$ 215$ billion (Hurd et. al, 2013). Additionally, cognitive decline negatively impacts personal wealth and retirement savings (Smith et. al, 2010 and Banks and Oldfield, 2007). Suboptimal pension and asset management, by cognitively impaired individuals, may cause significant welfare loss for the elderly and their households. Costs associated with cognitive decline will likely rapidly rise with the aging of the Baby-Boom generation.

Normal cognitive aging is aggravated by retirement. In addition to the negative income shock following retirement, loss of an engaged lifestyle, including loss of a work related social network, negatively impacts cognitive function post-retirement (Rohwedder and Willis, 2010). Little however is known of alternative forms of engagement that can serve as a substitute for the separation from formal employment, thereby mitigating cognitive decline among the elderly. This study investigates volunteering participation as a protective factor that can mitigate cognitive decline. In comparison to other post-retirement activities, volunteering is unique in its ability to provide mental, physical and social stimulation simultaneously.

This study makes two contributions to the existing literature. First, it contributes to the literature on determinants of cognitive ability. Specifically, the study evaluates if volunteering of any kind and at levels typically seen in the population can mitigate cognitive decline in a nationally representative sample of elderly Americans. Second, the study contributes to the large existing literature on health benefits of pro-social behavior. This study provides the first causal evidence of a favorable impact of pro-social behavior on individual (cognitive) health.

The study uses a fixed effects-instrumental variable (FE-IV) strategy to provide the first population-level evidence of a plausibly causal impact of volunteering on cognitive decline. Onset of daily living limitations of spouses provide an exogenous shock to the individual's 
time constraint that forces a reallocation of time. Subject to the identifying assumption that changes in spousal daily living limitations do not directly impact the individual's cognitive decline ${ }^{1}$ the results show that volunteering has a causal protective effect on cognitive decline in the elderly. The estimate of the protective effect of volunteering on cognitive decline is robust to a wide array of additional socioeconomic and demographic controls.

The study has several policy implications. If volunteering can help compensate for the loss of engagement post-retirement, individuals can use this to mitigate cognitive decline associated with aging. Given the large health care and personal costs associated with cognitive decline, a protective effect of volunteering on cognitive decline would imply large health care and personal gains. Volunteers could also generate large positive externalities by providing useful services to otherwise under served communities. The results are also conceptually important for the large literature on the benefits of pro-social behavior on the doer (Konrath, 2012). Despite being vast, the existing literature is uninformative on the causal effects at the population level.

The structure of the remaining paper is as follows. The next section places this study in context of the existing literature linking pro-social behavior with cognitive decline. This is followed by an overview of the Heath and Retirement study with an in depth discussion of the key independent variable, volunteering participation and the outcome of interest, cognitive decline. Section 3 also discusses the fixed effects-instrumental variable method for the estimation of the causal impact of volunteering on cognitive decline, along with the underlying identification assumptions and their validity in the current context. Results are presented in Section 4. Section 5 provides estimates of the financial implications of volunteering for cognitive decline. Section 6 concludes.

\section{Past Literature}

Age, gender, income, race (Karlamangla et al., 2009), education (Banks and Mazzonna, 2012), in-utero and early life conditions (Case and Paxson, 2009; Cunha and Heckman,

\footnotetext{
${ }^{1}$ Detailed discussion of conditions under which the identifying assumption is expected to hold and its implications for our analyses presented in Section 3 Data and Methods below.
} 
2007), non-work related social network size (family and friends; Cornwell and Waite, 2009; Hawkley and Cacioppo, 2010), marital status (Karlamangla et al., 2009), health, engagement in cognitive and physical activity and individual personality traits like conscientiousness and extroversion (James et al., 2011; Wilson et al., 2007) have been associated with old age cognitive decline (Mendez and Adair, 1999; Factor-Litvak and Susser, 2004). Findings from these earlier descriptive studies cannot be interpreted causally. Moreover, even though knowledge of the socioeconomic and demographic predictors of cognitive decline help identify vulnerable individuals, these factors are infrequently malleable for the already adult population facing age related cognitive decline, limiting their usefulness as policy instruments.

Retirement is a plausible predictor of cognitive decline that individuals can somewhat influence. Conceptually, the negative income shock and the loss of a work related social network could lead to a rapid decline in cognitive function post-retirement (Rohwedder and Willis, 2010; Mazzonna and Peracchi, 2012). But, empirical evidence of such a relationship is mixed. For instance Coe et al. (2012) find no clear relationship between retirement duration and later-life cognition for white-collar workers and even a favorable impact of retirement on the cognitive wellbeing for blue-collar workers.

Looking at other deliberate behavior that individuals can use to mitigate cognitive decline, the Experience Corps randomized experiment provides encouraging evidence suggesting a potentially protective, causal effect of volunteering on cognitive decline. The study finds significantly lower memory loss in seniors who were assigned to cognitively demanding, high intensity volunteering roles (Carlson et. al, 2008; Fried et. al, 2004). The results from the study are encouraging but their external validity is not known. Firstly, the treatment was not a typical volunteering experience. The 352 adults, 60 years and older, who were randomly treated were assigned to tutoring school students for 15 or more hours per week for a year or more. Prior to starting the tutoring, volunteers received group training for a week and then served as volunteers in groups they had trained with. Therefore, the favorable causal effect of the volunteering could be due to several atypical aspects of the Experience Corps experiment. First, Experience Corps volunteers volunteered for at least 15 hours per week compared to most conventional volunteering commitments of about two 
hours per week. Second, the Experience Corps volunteers tutored school students, an activity that is cognitively more demanding than many of the other usual volunteering activities like, shelving or serving in a soup kitchen. Third, the Experience Corps experiment started with a week of training that in itself would be educational and could favorably impact cognitive scores, even without the subsequent volunteering. Finally, identification of the causal effect of volunteering on cognitive ability was further complicated by the fact that to be included in the treatment group the individual, at baseline, had to be cognitively intact with an above average cognitive score. ${ }^{2}$ Since rate of cognitive decline may depend upon baseline cognitive ability, some of the 'causal' effect may in fact be a selection effect. This study explores the generalizability of the kind of results produced by the Experience Corps experiment to the general population. Comparing volunteers to non-volunteers, all forms of volunteering and individuals along the entire distribution of baseline cognitive ability we estimate the impact of volunteering on cognitive decline.

A parallel literature has found a positive association between volunteering and the volunteer's subjective mental wellbeing (Konrath, 2012; Lum and Lightfoot, 2005). Subjective mental wellbeing includes emotions like depression, feelings of isolation and levels of happiness. ${ }^{3}$ In contrast, cognitive functioning measures the respondent's intelligence and this distinction is critical. ${ }^{4}$ Depression and cognitive ability are theoretically and empirically different constructs. In this study we explore if deliberate social behavior, specifically volunteering, can slow down the TICS score based measure of cognitive decline.

\footnotetext{
${ }^{2}$ Cutoff cognitive score of 24 compared to the average of about 22.91 for a similar cohort (refer Appendix Table A.1).

${ }^{3}$ The HRS includes the Center for Epidemiologic Studies Depression (CESD) scale to measure the emotional wellbeing of the respondent. The CESD scale captures emotions experienced by the respondent: depression, everything is an effort, sleep is restless, felt alone, felt sad, and could not get going, all or most of the time (negative emotions), felt happy and enjoyed life, all or most of the time (positive emotions). All analyses includes, as a control, the individual's CESD scale. However, results remain mostly unchanged if we re-estimate the impact of volunteering on cognitive ability without controlling for the individual's CESD scores (refer Appendix D).

${ }^{4}$ See below detailed discussion of HRSs' TICS cognitive ability scores.
} 


\section{Data and Methods}

The study uses seven waves (1998-2010) of the nationally representative Health and Retirement Study, a study of Americans aged 50 years and older. ${ }^{5} 6$ The dependent variable is the modified version of the Telephone Interview for Cognitive Status (TICS) score based on Folsteins Mini Mental Status Examination (MMSE; Lanska et. al (1993); Roccaforte et. al (1992); Wilson and Bennett (2005)). The HRS version of the TICS evaluates two main components of the respondent's cognitive status - fluid and crystallized intelligence. Crystallized intelligence/ability is defined as factual knowledge, which is likely to continue growing, even if slowly over one's lifetime. Consequently, cognitive decline due to aging does not typically refer to declines in crystallized intelligence. Cognitive decline customarily refers to slowing down of the speed of information processing, i.e, decline in fluid intelligence.

In the HRS, crystallized intelligence is quantified based on the respondent's ability to correctly report 'today's date' (Month, day, year and day; score 0-4), identify two objects for a total score of 0-2 and name the current President and Vice President of the United States (0-2 points) for a total crystallized intelligence score ranging from 0-8. Fluid intelligence is measured on a scale of 0-27 and captures memory and working memory status. Memory is tested using immediate and delayed word recall with a score ranging between 0-20. Working memory is assessed using two tests. First, the serial 7's subtraction test asks the respondent to subtract 7 from 100 and continue subtracting from each subsequent number for a total of five trials with a resulting score ranging from 0-5. The backward count from 20 task requires the respondent to count backwards from 20 earning a total of 2 points. The questions do not have to be answered within a limited time, allowing participants ample opportunity to respond. The TICS scores have high sensitivity and specificity to clinically determined cognitive decline (Castanho et al., 2014; de Jager et al., 2003), a precursor to mild cognitive impairment (MCI), Alzheimer's disease and dementia.

\footnotetext{
${ }^{5}$ Two recent waves of the HRS from 2012 and 2014 are currently available but not included as they do not include the cognition module.

${ }^{6} \mathrm{HRS}$ may include both spouses in the sample but, for our analyses we have only retained the main HRS respondent as a distinct observation. Spousal health limitations are used as instrumental variables for identification and including both spouses in the sample would imply that the IV of one observation will be the control for another, making the interpretation of estimates from such a sample less intuitive.
} 
Figure 1: TICS cognitive ability scores by age.

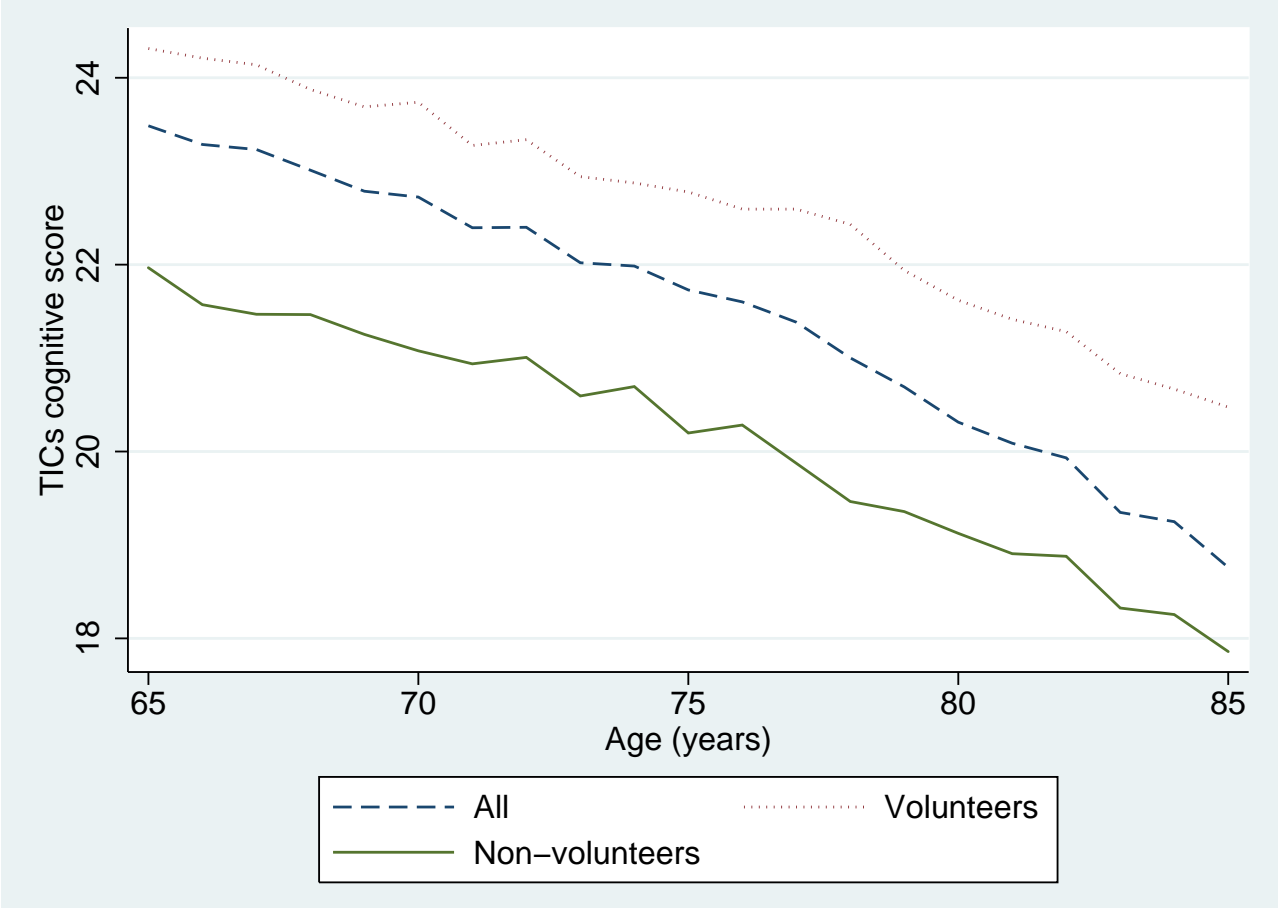

For the sample as a whole, the mean TICS cognitive score is 22.91 (out of 35), with scores being on average 2.41 points higher for the subsample of volunteers compared to nonvolunteers, a difference which is statistically significant at the 1 percent level. Similar patterns emerge when the two components of TICS cognitive scores are considered separately. Volunteers have significantly higher crystallized and fluid intelligence scores than non-volunteers. Not surprisingly, Figure 1 shows that cognitive ability declines with age for both volunteers as well as non-volunteers with TICS cognitive scores being consistently higher for volunteers than non-volunteers at all ages.

Volunteering is measured as the sum of hours spent in the past 12 months "doing volunteer work for religious, educational, health-related or other charitable organizations" (formal volunteering) and "helping friends, neighbors, or relatives who did not live with you and did not pay you for the help" (informal volunteering). 56 percent of the HRS sample reports doing some volunteering in the past 12 months. An average volunteer reports 136 hours of volunteering in the past year i.e. about 2.5 hours of volunteering per week. Next, volunteering status by age are presented in Figure 2. Not only does the proportion of volunteers decline with age (Figure 2), Figure 3 shows that at higher ages volunteers volunteer a lot fewer 
Figure 2: Distribution of volunteering status by age categories.
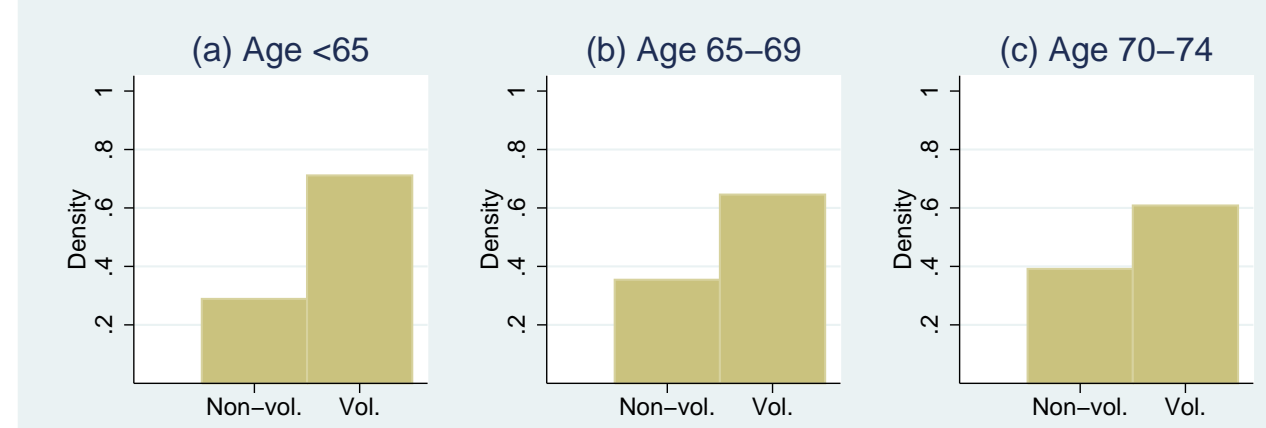

(d) Age 75-79

(e) Age 80-84
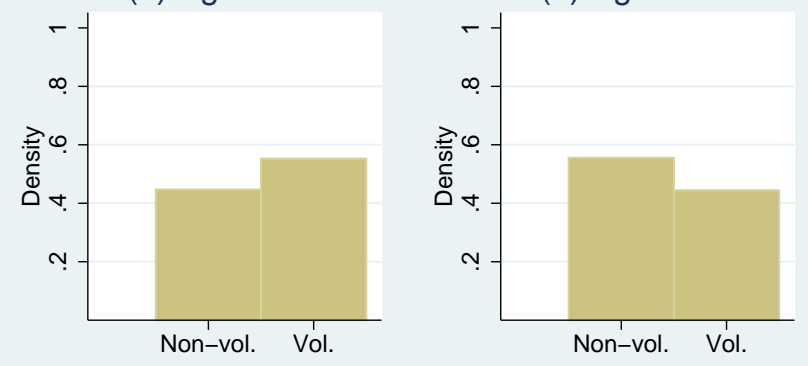

(f) Age 85+

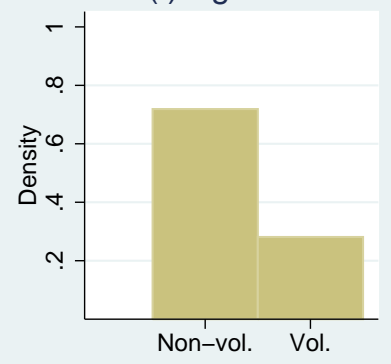

hours.

Volunteers and non-volunteers differ significantly from each other in other observable characteristics as well. Volunteers, on average, have a higher proportion of males, whites, are likely to be younger, have higher mean household income, more religious, more educated, with fewer children, retired, less likely to be smokers and are healthier than non-volunteers. ${ }^{7}$ Given their observed differences, it is quite likely that volunteers differ from non-volunteers in unobserved characteristics as well.

Cognitive ability of individual $i$ in wave $t$ is modeled as:

$$
C_{i, t}=\beta_{0}+\beta_{1} V_{i, t}+\beta_{2} X_{i, t}+\alpha_{i}+u_{i, t}
$$

$C_{i, t}$ is a function of the respondent's hours of volunteering $V_{i, t}$, a set of relevant time constant and time varying independent explanatory variables $X_{i}$ including gender, race, retirement status, physical and mental health, lifestyle factors and age of the individual and, $\alpha_{i}$ that captures individual level time constant unobserved confounders of pro-social behavior and

\footnotetext{
${ }^{7}$ Detailed decriptive statistics presented in Table A.1 of the accompanying Appendix.
} 
Figure 3: Hours of volunteering by age.

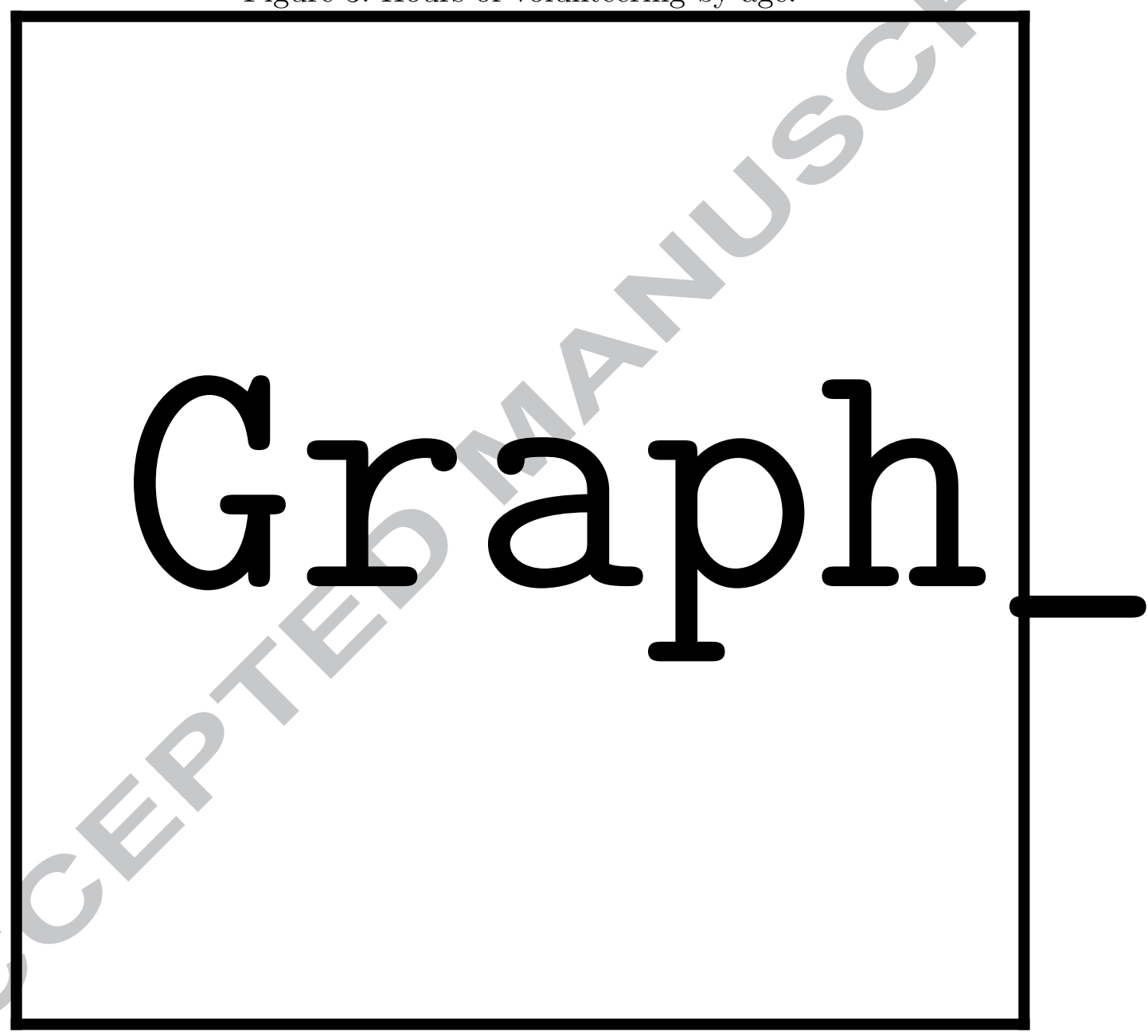


cognitive score like conscientiousness. $\beta_{1}$ denotes the impact of volunteering on cognitive function and is estimated using the fixed effect - instrumental variable (FE-IV) estimation. Using fixed effects allows to control for time-constant confounders; adding instrumental variable addresses endogeneity concerns that arise from time-varying factors. Regressions are implemented use the Stata package xtivreg2 ( Schaffer ( 2010)). In so doing, the FE-IV estimates of the impact of changes in volunteering on cognitive decline can be interpreted causally, given the validity of the identifying assumptions. That is, all else remaining constant, a positive value of the estimated $\beta_{1}$ would capture the increase in TICS cognitive ability score following an additional hour of volunteering. Alternately, a negative value of the estimated $\beta_{1}$ would capture the decline in the TICS cognitive ability scores if volunteering time falls by an hour, keeping everything else unchanged. 8 The FE-IV method works as follows.

First, the FE-IV method uses first differences to eliminate time constant individual level confounders, thereby estimating the impact of changes in hours spent volunteering on changes in TICS score of cognitive function. Examples of such time constant confounders of volunteering and cognitive function include, for instance, personality traits like conscientiousness, extroversion, social connectedness or early life experiences that remain fixed over the individual's lifetime. For instance, a more socially connected person may volunteer more and also have higher TICS cognitive scores, a positive relationship. In absence of controls for unobserved social connectedness the coefficient on volunteering will pick up some of this effect and will therefore be biased upward.

A second source of bias, remaining in the fixed effects estimates, are time varying unobserved confounders of changes in hours spent volunteering and changes in TICS scores of cognitive status. For instance in our HRS sample, $81 \%$ of the individual's who reported

\footnotetext{
${ }^{8}$ In theory, the linear specification implies that transitions in-and-out of volunteering would entail corresponding changes in the individuals TICS cognitive ability scores. In practice however, the data suggests that frequent switching is not that common. Classifying individuals into mostly non-volunteer (volunteers for $0-2$ waves out of total 9 waves), switcher (volunteer in 3-5 waves) and mostly volunteer (volunteer for 6-9 waves out of total 9 waves) we find that only about $16 \%$ of the sample are switchers. $60 \%$ are mostly non-volunteers and the remaining are mostly volunteers. Moreover, these percentage are not sensitive to marginal changes in the cut-offs for classifying transitioning behavior. So the analyses, in practice is capturing sharp, persistent shifts in volunteering patterns and not frequent oscillations in-and-out of volunteering.
} 
volunteering in wave $t-1$ but not in wave $t$ experience no change in retirement status, $11 \%$ got retired and $7 \%$ reports working again after reporting their primary employment status as 'retired' in the previous wave. In contrast, the group who started volunteering, consists significantly more of new retirees $(14 \%)$ and has significantly fewer people with no change in retirement status (79\%). Similarly, compared to the group that stopped volunteering new volunteers were significantly younger, richer, less likely to remain single, changed their alcohol consumption behavior and reported fewer health problems. ${ }^{9}$ Given the large observed differences between individuals who stopped volunteering and those who started volunteering, the two groups are likely to differ in their unobserved characteristics as well. Consequently, a fixed effects regression that does not control for unobservable time varying confounders would be insufficient for causal inference of the impact of volunteering on cognitive decline.

Omitted variable bias due to unobserved, time varying confounders may be positive or negative. In case of confounders that lower volunteering time but increase cognitive function, like meditation, sleeping or exercise (Park et. al, 2014, LaMore et. al 2013, Wells et. al 2013 and Tamaki 2013), omission will bias our estimates of the impact of changes in volunteering on changes in cognitive function downwards. On the other hand, omitting unobserved changes in health, that may be positively related to both volunteering and cognitive function, will bias our results upward. The overall direction of the omitted variable bias due to time varying confounders is an empirical issue. I control for the bias introduced by time varying confounders by instrumenting the potentially endogenous hours of volunteering.

To be an instrument the variable should significantly impact hours of volunteering, without directly affecting the person's TICS cognitive scores. Changes in spousal activities of daily living, instrumental activities of daily living and mobility limitations are used as the three instruments for changes in hours spent volunteering. Henceforth, 'spousal limitations' collectively refers to the three instruments - limitations on activities of daily living (example: bathing, eating, dressing, walking across a room, getting in or out of bed; range 0-5), limitations on instrumental activities of daily living (example: using a telephone, taking medication, handling money; range 0-3) and mobility limitations (example: walking several

\footnotetext{
${ }^{9}$ Refer Appendix Table A.2 Panel A for detailed descriptives by change in volunteering status.
} 
blocks, walking one block, walking across the room, climbing several flights of stairs and climbing one flight of stairs; range 0-5). Summed together, spousal limitations range from 0-13. $70.85 \%$ of the sample have no spousal limitation, $11.66 \%$ of the sample experiences one limitation, $6.12 \%$ has two, $3.63 \%$ has three, $2.71 \%$ has four and $5 \%$ suffers from five or more. On average, spouses are 1.5 times more likely to experience increase in limitations than decrease in limitations over time.

To illustrate how spousal limitations may be a relevant instrument, consider the onset of a new limitation. Increases in spousal limitations, exogenously increases demands on the respondents time in order to help their spouse, constraining the time left for volunteer work. Validity of the instrument requires that care-giving not directly impact the respondent's TICS cognitive function score. Conceptually, for instance, when faced with new spousal limitations, the respondent's ability to recall that scissors are 'usually used to cut paper' or 'What year is it?' should remain largely unaffected. Tiredness from care-giving may increase their response time but it is unlikely that they won't be able to answer these questions, leaving their TICS scores mostly unimpacted. As noted in Section 2 above, for this reason TICS scores are insensitive to depression, except in cases of extreme depression. One extremely stressful care-giving situation is caring for a spouse with Alzheimer's disease or dementia. To ensure that our instrument is not impacted by these extreme cases we eliminate from our main analysis individual's whose spouses are diagnosed with Alzheimer's disease or dementia in any wave, resulting in a loss of $1.38 \%$ of the original sample. ${ }^{10}$ Another, source of endogeneity could be reverse causality where declining cognition forces the individual to stop volunteering. This would be particularly problematic if cognitive decline of the respondent is highly correlated to spousal daily limitations in the elderly which would render our instrument invalid. We refer to the literature on assortative mating on health in spouses to check if this may be a concern. Jain and Ma (2017) and references therein provide detailed discussions of and tests for the correlation between spouses' healths. Specifically, they note correlations between physical attributes or intelligence of spouses but find no statistically

\footnotetext{
${ }^{10}$ Results are not sensitive to the inclusion of individual's with spouses suffering from Alzheimer's disease or dementia. Coefficient estimates for all sensitivity checks are available upon request from the author.
} 
significant evidence of assortative mating patterns where individuals with certain cognitive decline patterns disproportionately match with individuals with certain physical health limitations. Such a scenario seems particularly unlikely since the timing of marriage mostly preceeds, by several decades, development of spousal physical limitations.

Finally, the FE-IV analysis also includes as controls a comprehensive set of time varying observed confounders of hours of volunteering and cognitive decline. ${ }^{11}$.

No observed differences are observed between respondents with spousal limitations and those without i.e. - the two subsamples are balanced. ${ }^{12}$ Had the IV spousal limitations been predictive of changes in observed characteristics, there would be concern that respondents with more spousal limitations were cognitively different from respondents with fewer spousal limitations causing bias in the effect of volunteering. Overall, this evidence supports the validity of spousal limitations as an instrument for volunteering.

The next section presents the FE-IV regression results, robustness checks and further quantitative evidence in support of the identification strategy and results.

\section{Regression results}

Table 1 presents regression results for the impact of the number of hours spent volunteering on the total TICS score of cognitive ability (column I) as well as on fluid (column II) and crystallized intelligence scores (column III) separately. OLS results, in row (1), show a statistically significant but small positive impact of hours of volunteering on cognitive ability scores. The OLS coefficient of 0.0044 implies that for an average individual who is volunteering about 100 hours per year, i.e. 2 hours per week, volunteering increases the TICS cognitive score by $0.0044^{*} 100 / 4.78=0.1$ of a standard deviation increase in the MMSE scores. Expectedly, the impact of volunteering on cognitive decline is associated more strongly with fluid intelligence (0.0039) thank crystallized intelligence (0.00049).

\footnotetext{
${ }^{11}$ Many of the included controls like household income, education, employment status, family and social structure, lifestyle factors and individual fixed effects could potentially be shared confounders of physical and mental health and cognitive ability of spouses and their inclusion in the analyses would further mitigate sources of endogeneity

${ }^{12}$ Refer Appendix A and Table A.2 Panel B for details.
} 


\section{ACCEPTED MANUSCRIPT}

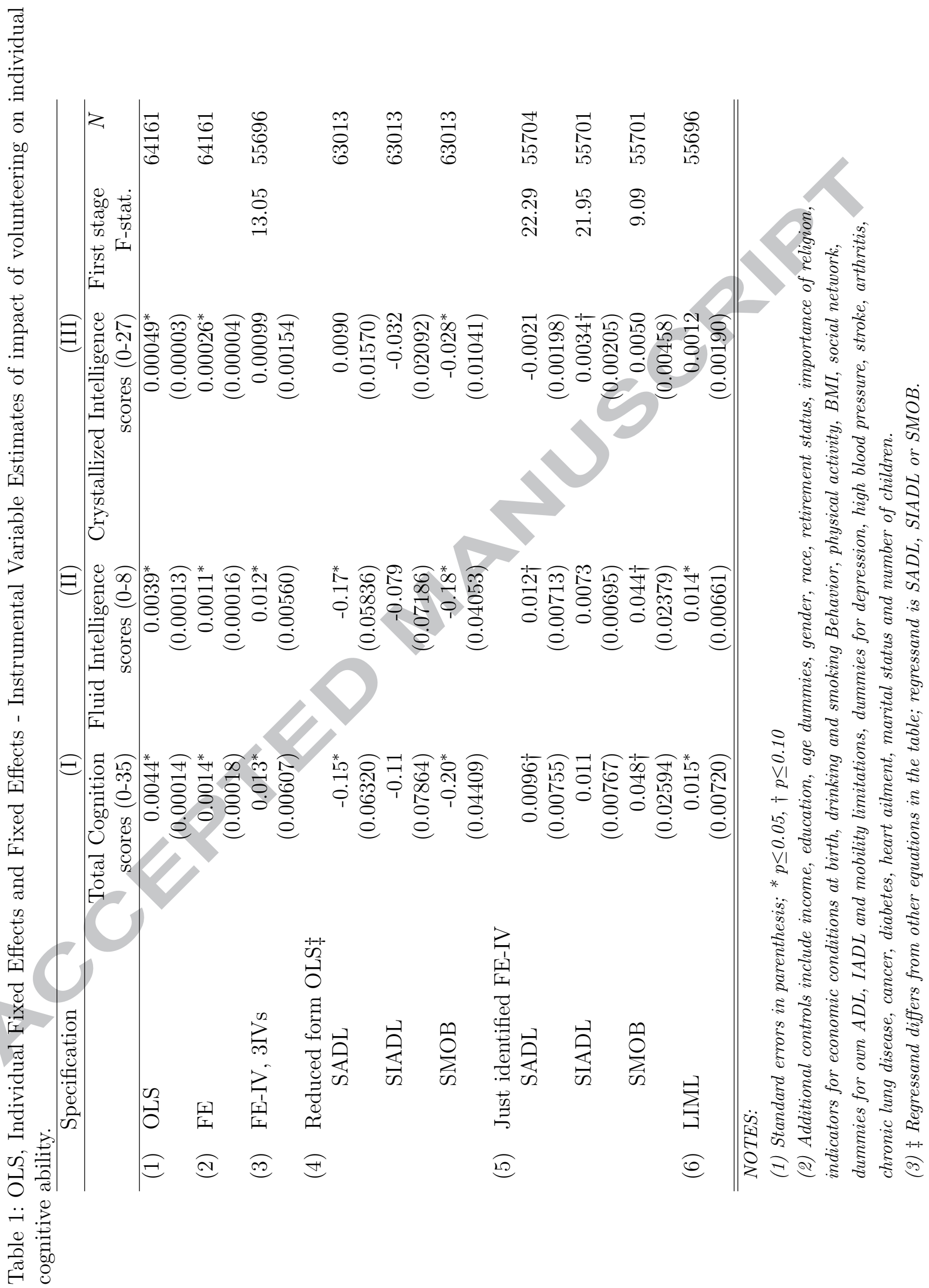


The fixed effects estimates of the association between the change in volunteering and cognitive decline in Table 1 row (2), control for time constant unobserved heterogeneity. The FE estimate of 0.0014 in row (2) column (I) is about a third in magnitude to the OLS estimates. Smaller FE coefficients indicate that the time constant unobserved heterogeneity must be positively correlated to volunteering.

Results from the FE-IV specification are presented in Table 1 row (3). We first check for the strength of the three instruments - spousal activities of daily living limitations, instrumental activities of daily living limitations and spousal mobility limitations - using the heteroscedasticity robust Kleibergen-Paap F-statistic from the first stage. The F-statistic of 13.05 (Table 1, row 3, column 4), exceeds the Stock and Yogo (2005) critical value of 9.08 at a $5 \%$ significance level for a $10 \%$ maximal bias in IV relative to OLS and is close to the critical value of 13.91 at a $5 \%$ significance level for only a $5 \%$ maximal IV bias relative to the OLS. Hence, we rule out weak instruments.

Controlling for time constant and time varying confounders, produces a significant positive impact of volunteering on cognitive ability. ${ }^{13}$ Considering the magnitude, the FEIV estimate implies that a 100 hours of volunteering per year, would result in a third $\left(\left(0.013^{*} 100\right) / 4.78\right)$ of a standard deviation increase in the TICS cognitive score. The increase in the coefficient from the FE to the FE-IV estimates suggests a net negative correlation between omitted time varying confounders and the individual's cognitive ability. For instance, omitted time spent sleeping or doing physical exercise might bias the coefficient on volunteering downwards but are linked to slower cognitive decline. Our FE-IV regression corrects for this downward bias in our FE estimates thereby pushing the coefficient upwards. Finally, consistent with the conceptual framework and larger likelihood of increasing than decreasing spousal limitations in an elderly sample, the significant impact of volunteering on cognitive ability are entirely driven by worsening spousal limitations. ${ }^{14}$

\footnotetext{
${ }^{13}$ Income, education, age, gender, race, retirement status, religiosity, smoking status, alcohol use, physical activity, BMI, social network and measures of physical and mental health are included as other predictors of cognitive decline. In line with previous literature, higher income and education, younger age, bigger social network, being white and higher level of physical activity are predictors of slower cognitive decline.

${ }^{14}$ Focusing on observations with worsened (increased) spousal limitations our estimate of the impact of volunteering on cognitive ability is .015 , which is statistically significant and very similar to the estimates in Table 1 for the full sample. On the other hand, for individuals whose spouses limitations decreased the
} 
Three tests are performed to check for signs of potential bias in the FE-IV estimates (Angrist and Pischke (2008)). First, we estimate separate reduced form regressions of each of the three instruments - spousal activities of daily living (SADL), spousal instrumental activities of daily living (SIADL) and spousal mobility limitations (SMOB) - on the dependent variable, cognitive ability of the individual. Results presented in row (4) of Table 1 show a significant negative relationship between changes in both SADL as well SMOB and changes in volunteering. The somewhat weaker association between changes in SIADL and volunteering is reasonable since SIADL activities, like using the telephone or handling money, are activities that spouses may already be doing for each other/together as an economic unit and as such the onset of new SIADL may not impose an increased burden on the individual. Overall, the significant reduced form relationship between the individual IVs and cognitive decline is further suggestive of a causal relationship between volunteering and cognitive ability.

Second, three just identified models are estimated using one instrument at a time; the idea being that a just identified model is median unbiased and therefore less likely to be subject to a weak instrument problem. Results are presented in row (5) in Table 1. The coefficients from the just identified models with SADL or SMOB as the IVs look qualitatively similar to those from the over identified model and reiterate a protective impact of volunteering on cognitive decline. Once again, the results from the just identified model using SIADL as the IV are insignificant and not surprising given the inherently different nature of SIADL. Although, the just identified models give us similar results, the over-identified model performs marginally better in terms of balancing the observable health outcomes of individuals and is therefore retained as the preferred specification.

Finally, row (6) presents the limited information maximum likelihood (LIML) estimates. LIML estimates are less precise than 2SLS but also less biased. Comparing the FE-IV estimates in row (3) to the LIML estimates in row (6) the two models are quantitatively and qualitatively similar, further increasing confidence in the estimates.

estimate of the impact of volunteering on cognitive ability from the FE-IV specification is almost 0. Detailed estimation results available upto request from author. 
Considering the causal impact of volunteering on fluid and crystallized intelligence separately, FE-IV estimates in row (3), columns (II) and (III) show that volunteering is primarily protective of the fluid intelligence component of cognitive ability. This is in line with our understanding of age related cognitive decline, which negatively impacts the individual's speed of information processing.

Results are similar when types of volunteering - formal and informal - are investigated separately. Results are also insensitive to the method used to deal with missing values dummies for missing or imputed values generated by multiple imputations. Results are also robust to corrections for potential attrition using inverse estimated attrition probabilities (Becketti et. al, 1988).

Next, we checked the extent to which the impact of volunteering on cognitive decline, instrumented by spousal limitations, is mediated by respondent's retirement status, physical health and depression. To do so, we re-estimated the FE-IV specifications without controlling for whether the respondent is retired or not, her physical health and CESD score for depression. The results are very similar suggesting that volunteering is directly protective of cognitive ability and the effect is not mediated through these covariates. ${ }^{15}$

Finally, a falsification test is conducted by regressing cancer on volunteering. Intuitively, volunteering cannot causally impact cancer. Hence, if the falsification test finds a significant causal effect of volunteering, instrumented with spousal limitations, on cancer it would suggest that spousal limitations are directly impacting respondent's cancer through a second channel, such as, shared eating habits of spouses that would confound spousal limitations and individual cognitive ability. Results of this falsification test are presented in Table 2. Excluding a control for cancer, columns (1), (3) and (5) reproduce the OLS, FE and FE-IV results of the impact of volunteering on cognitive ability. Estimates are qualitatively and quantitatively similar to our main results in Table 1; volunteering is significantly protective of cognitive decline. Columns (2), (4) and (6) present the corresponding OLS, FE and FE-IV estimates of the impact of volunteering on cancer. The OLS and FE cancer results, like cog-

\footnotetext{
${ }^{15}$ Mediation tests presented in Table B.2 of the accompanying Appendix along with detailed results of all robustness checks.
} 
nitive ability, suggest an association between volunteering and better health. However, this association does not persist in the FE-IV model. This falsification test, in addition with our balancing tests (Appendix Table A.2) are consistent with the validity of the identification assumption.

Table 2: OLS, Individual Fixed Effects (FE), and Individual Fixed Effects - Instrumental Variable (FE-IV) estimates of the impact of volunteering on individual cognitive ability and cancer.

\begin{tabular}{lcccccc} 
& $(1)$ & $(2)$ & $(3)$ & $(4)$ & $(5)$ & $(6)$ \\
& OLS & OLS & FE & FE & FE-IV & FE-IV \\
Cognition $\dagger$ & Cancer & Cognition $\dagger$ & Cancer & Cognition $\dagger$ & Cancer \\
\hline Volunteering & $0.00442^{*}$ & $-0.00002^{*}$ & $0.00141^{*}$ & $-0.00007^{*}$ & $0.01300^{*}$ & -0.00010 \\
& $(0.00013)$ & $(0.00001)$ & $(0.00017)$ & $(0.00001)$ & $(0.00606)$ & $(0.00034)$ \\
& & & & & {$[13.06]$} & {$[13.06]$} \\
\hline $\mathrm{N}$ & 64161 & 64161 & 64161 & $64161)$ & 55696 & 55696 \\
\hline \hline NOTES: & & & \\
(1) ${ }^{\dagger}$ Identical specification as in Table 1, column I, rows 1-3 but without control for cancer. \\
(2) standard errors in parentheses, ${ }^{*} p<0.05 ;$ [ ] first stage F-statistic
\end{tabular}

\section{$5 \quad$ Monetary implications}

We replicate and extend the model of Hurd et. al, 2013 to estimate the savings in total health care cost of dementia associated to volunteering. Hurd et. at (2013) find that in $201014.7 \%$ of persons ages 70 years and older suffered from dementia, an extreme form of cognitive decline. The authors use the 856 persons Aging, Demographics and Memory Study (ADAMS) subsample of the HRS, with clinical assessments for dementia to estimate a probability model identifying the significant predictors of dementia. The resulting estimates are then used to predict individuals with dementia in the larger, nationally representative, HRS sample. Finally, merging the HRS with restricted health care cost data the authors estimate the total monetary cost of dementia in 2010 to be between $\$ 157-\$ 215$ billion.

Our replication results accurately predict $76.9 \%$ of patients in the ADAMS subsample with clinically diagnosed dementia. The sensitivity of our replication study is comparable to that of Hurd et. al (2013) who accurately predict $77.9 \%$ of the clinically diagnosed dementia patients. In terms of specificity, our re-estimation correctly classifies $88.9 \%$ of non-demented 
cases compared to $89.8 \%$ by Hurd et. al (2013). This exercise assures us that our replication of the Hurd et. al (2013) estimations is reasonably accurate. ${ }^{16}$

Next, the Hurd et. al (2013) model is extended by including volunteering as an additional predictor of dementia. The extended model predicts 14 fewer cases, i.e. a $5.9 \%$ decline in the predicted incidence of dementia. Assuming that this also results in a $5.9 \%$ savings in health care costs of dementia, volunteering is associated with a health cost savings of about $\$ 9.26$ $\$ 15.16$ billion in 2010 dollars. This is likely to be a lower bound of the health care savings associated to volunteering as it does not account for health care spending on patients with cognitive impairment but not dementia. In addition it does not include the monetary value of the positive externalities generated by volunteering.

\section{Conclusion}

Using seven waves of the nationally representative Health and Retirement Study (HRS) sample of Americans over the age of 50, this study estimates the impact of volunteering on cognitive decline. Two potential sources of endogeneity of volunteering, time constant and time varying, are mitigated by using a fixed effects-instrumental variable methodology. First differencing, to eliminate time constant confounders of volunteering and cognitive ability, followed by instrumenting changes in volunteering with changes in spousal limitations, to account for time varying sources of unobserved heterogeneity, yields plausibly causal estimates of the effect of volunteering on cognitive ability. Onset of spousal limitations, provides an exogenous shock to the time constraint of the respondent thereby reducing their volunteering participation, making it a relevant instrument for changes in volunteering. Validity of the instrument is supported by a battery of balancing, statistical and falsification tests. Results show a significant protective effect of volunteering on cognitive decline.

The current work also has two limitations. First, this study is not a randomized control trial. While a RCT would leave little, if any, doubt about internal validity, it would not establish external validity, arguably an advantage of the current study. The current study, using a

\footnotetext{
${ }^{16}$ See Appendix for details.
} 
nationally representative sample of individuals along the full continuum of baseline cognitive ability and volunteering roles, provides plausibly causal estimates of the protective impact of volunteering on cognitive decline. Second, the assesment of volunteering in the HRS does not permit investigation of the mechanism through which volunteering has a protective effect on cognitive ability. More information on the nature of volunteering activity, for instance, whether it evokes mental, physical and/or social engagement would help understand exactly how volunteering mitigates cognitive decline.

Finally, the study makes two important contributions. First, to the best of our knowledge, this is the first study to provide evidence of a plausibly causal relationship between volunteering and cognitive decline using a nationally representative data. This suggests that volunteering is a viable alternative to formal employment in the mitigation of cognitive decline. In terms of costs, calculations suggest that volunteering could reduce health care spending by about $6 \%$; $\$ 9-15$ billion in 2010 dollars. Second, this study makes an important contribution to the large, existing, descriptive literature on health benefits of prosocial behavior for the doer. The current study provides the first causal evidence of a protective effect of volunteering on individual (cognitive) health. 


\section{References}

Alpert J.E., Uebelacker L.A., McLean N.E., Abraham M., Rosenbaum J.F. and Fava M. (1995), The Mini-Mental State Examination among Adult Outpatients with Major Depressive Disorder, Psychotherapy and Psychosomatics, Vol. 63, pp. 207211.

Angrist J.D. and Krueger A.B. (2001), Instrumental Variables and the Search for Identification: From Supply and Demand to Natural Experiments, Journal of Economic Perspectives, Vol. 15(4), pp. 6985.

Angrist J.D. and Pischke J-S. (2008), Mostly Harmless Econometrics: An Empiricist's Companion, Princeton, NJ: Princeton University Press.

Banks J., and Mazzonna F. (2012), The effect of education on old age cognitive abilities: evidence from a regression discontinuity design, The Economic Journal, Vol. 122, pp. 418-448.

Banks J., and Oldfield, Z. (2007), Understanding pensions: cognitive function, numerical ability and retirement saving, Fiscal Studies, Vol. 28, pp. 143-170.

Becketti S., Gould, W., Lillard, L., and Welch, F. (1988), The Panel Study of Income Dynamics after Fourteen Years: An Evaluation', Journal of Labor Economics, Vol. 6, pp. $472-92$.

Carlson M.C., J.S. Saczynski, G.W. Rebok, T. Seeman, T.A. Glass, S. McGill (2008), Exploring the effects of an everyday activity program on executive function and memory in older adults: Experience Corps, The Gerontologist, Vol. 48, pp. 793801.

Case A. and Paxson, C. (2009), Early Life Health and Cognitive Function in Old Age, American Economic Review: Papers and Proceedings, Vol. 99(2), pp. 104-109.

Castanho T.C., Amorim L., Zihl J., Palha J.A., Sousa N. and Santos N.C. (2014), Telephonebased screening tools for mild cognitive impairment and dementia in aging studies: a review of validated instruments, Frontiers in Aging Neuroscience, Vol. 6, pp. 1-17.

Cornwell E.Y. and Waite L.J. (2009), Social Disconnectedness, Perceived Isolation, and Health among Older Adults, Journal of Health and Social Behavior, Vol. 50(March), pp. $31-48$.

Coe N.B., von Gaudecker H-M., Lindeboom M. and Maurer J. (2012), The Effect of Retirement on Cognitive Functioning, Health Economics, Vol. 21, pp. 913-927.

Cunha F. and Heckman, J. (2007), The technology of skill formation, American Economic Review, Vol. 97, pp. 31-47. 
de Jager C.A., Budge M.M. and Clarke R. (2003), Utility of TICS-M for the assessment of cognitive function in older adults, International Journal of Geriatric Psychiatry, Vol. 18(4), pp. 318-24.

Dufouil C., Fuhrer R., Dartigues J-F. and Alperovftch A. (1996), Longitudinal Analysis of the Association between Depressive Symptomatology and Cognitive Deterioration, American Journal of Epidemiology, Vol. 144(7), pp. 634-641.

Factor-Litvak P., and Susser E. (2004), A life course approach to neuropsychiatric outcomes, in Kuh D., Ben-Shlomo Y., A life course approach to chronic disease epidemiology, 2nd edition, Oxford University Press, Oxford.

Fried L.P., Carlson M.C., Freedman M., Frick K.D., Glass T.A., Hill J., McGill S., Rebok G.W., Seeman T., Tielsch J., Wasik B.A., Zeger S. (2004), A social model for health promotion for an aging population: Initial evidence on the Experience Corps model, Journal of Urban Health, Vol. 81(1), pp. 6478.

Ganguli M., Du Y., Dodge H.H., Ratcliff G.G., Chang C.C. (2006), Depressive symptoms and cognitive decline in late life: a prospective epidemiological study, Archives of General Psychiatry, Vol.63(2), pp. 153-60.

Han L., McCusker J., Abrahamowicz M., Cole M. and Capek R.J. (2006), The temporal relationship between depression symptoms and cognitive functioning in older medical patients-prospective or concurrent?, The journals of Gerontology. Series A, Biological Sciences and Medical Sciences, Vol. 61(12), pp. 1319-23.

Hawkley L.C. and Cacioppo J.T. (2010), Loneliness Matters: A Theoretical and Empirical Review of Consequences and Mechanisms, Annals of Behavioral Medicine, Vol. 40, pp. 218-227.

Hurd M.D., Martorell, P., Delavande, A., Mullen, K.J., and Landa K.M. (2013), Monetary Costs of Dementia in the United States, The New England Journal of Medicine, Vol. 368(14), pp. 1326-1334.

Jain U. and Ma M. (2017), mimeo.

James B.D., Wilson R.S., Barnes L.L. and Bennett D.A. (2011), Late-Life Social Activity and Cognitive Decline in Old Age, Journal of International Neuropsychol Soc, Vol. 17(6), pp. 998-1005.

Karlamangla A.S., Miller-Martinez D., Aneshensel C.S., Seeman T.E., Wight R.G. and Chodosh J. (2009), Trajectories of Cognitive Function in Late Life in the United States: 
Demographic and Socioeconomic Predictors, American Journal of Epidemiology, Vol. 170 (3), pp. 441-342.

Konrath S. (2012), The power of philanthropy and volunteering, in Interventions and Policies to Enhance Wellbeing, Felicia Huppert and Cary Cooper (Eds.), Wiley Press.

LaMore and Roraback, Robert Root-Bernstein; John Schweitzer ; James Lawton (2013), A young Picasso or Beethoven could be the next Edison, Economic Development Quarterly

Lanska D.J., Schmitt F.A., Stewart J.M., Howe J.N. (1993), Telephone-Assessed Mental State, Dementia, Vol.4, pp. 117119.

Lum T.Y. and Lightfoot E. (2005), The Effects of Volunteering on the Physical and Mental Health of Older People, Research on Aging January, Vol. 27, pp. 31-55.

Mazzonna F. and Peracchi F. (2012), Aging, cognitive abilities and retirement, European Economic Review, Vol. 56(2012), pp. 691-710.

McClellan M., McNeil B.J. and Newhouse J.P. (1994), Does More Intensive Treatment of Acute Myocardial Infarction in the Elderly Reduce Mortality, Journal of the American Medical Association, Vol. 272(11), pp. 859-867.

Mendez M.A. and Adair, L.S. (1999), Severity and Timing and Stunting in the First Two of Life Affect Performance on Cognitive Tests in Late Childhood, The Journal of Nutrition, Vol. 129, pp. 1555-1562.

Niti M., Yap K.B., Kua E.H. and Ng, T.P. (2009), APOE-epsilon4, Depressive Symptoms, and Cognitive Decline in Chinese Older Adults: Singapore Longitudinal Aging Studies, Journal of Gerontology: Medical Sciences, Vol. 64A (2), pp. 306-311.

Park D. C., Lodi-Smith, J., Drew, L., Haber, S., Hebrank, A., Bischof, G. N. and Aamodt, W. (2014), The Impact of Sustained Engagement on Cognitive Function in Older Adults: The Synapse Project, Psychological Science, Vol. 25(1), pp. 103112.

Roccaforte W.H., Burke W.J., Bayer B.L., Wengel S.P. (1992), Validation of a telephone version of the mini-mental state examination, Journal of American Geriatrric Soceity, Vol. 40, pp. 697702.

Rohwedder S. and Willis, R.J. (2010), Mental Retirement, Journal of Economic Perspectives, Vol. 24(1), pp. 119-138.

Schaffer M.E., 2010. xtivreg2: Stata module to perform extended IV/2SLS, GMM and $\mathrm{AC} / \mathrm{HAC}$, LIML and k-class regression for panel data models.

http://ideas.repec.org/c/boc/bocode/s456501.html 
Schweitzer I., Tuckwell V., O'Brien J. and Ames D. (2002), Is late onset depression a prodrome to dementia?, International Journal of Geriatric Psychiatry, Vol. 17(11), pp. 997-1005.

Smith J.P., McArdle J.J. and Willis R. (2010), Financial Decision Making and Cognition in a Family Context, The Economic Journal, Vol. 120(549), pp. F363-F380.

Stock J, Yogo M. (2005), Testing for weak Instruments in Linear IV Regression. In Andrews DWK Identification and Inference for Econometric Models, New York: Cambridge University Press; pp. 80-108.

Tamaki M., Huang T.R., Yotsumoto Y., Hämäläinen M., Lin F.H., Náñez Sr. J.E., Watanabe T. and Sasaki Y. (2013), Enhanced Spontaneous Oscillations in the Supplementary Motor Area Are Associated with Sleep-Dependent Offline Learning of Finger-Tapping Motor-Sequence Task, The Journal of Neuroscience, Vol. 33(3), pp. 13894.

Vinkers D.J., Gussekloo J., Stek M.L., Westendorp R.G.J. and van der Mast R.C. (2004), Temporal relation between depression and cognitive impairment in old age: prospective population based study, British Medical Journal, doi:10.1136/bmj.38216.604664.DE

Wells Gloria Yeh, Jennifer Wolkin, Roger B. Davis, Ted Kaptchuk, Daniel Press, Russell S. Phillips, Catherine Kerr, Robert B. Wall, Jacquelyn Walsh, Ying Tan, Rosa Spaeth and Jian Kong (2013), Stress reduction through meditation may aid in slowing the progression of Alzheimer's disease, Neuroscience Letters, Vol. 556(15).

Willis Robert J. (1999), Theory confronts data: How the HRS is shaped by the economics of aging and how the economics of aging will be shaped by the HRS, Labour Economics, Vol. 6(2), pp. 119145.

Wilson R.S. and Bennett D.A. (2005), Assessment of cognitive decline in old age with brief tests amenable to telephone administration, Neuroepidemiology, Vol. 25, pp.1925.

Wilson R.S., Schneider, J.A., Arnold, S.E., Bienias, J.L. and Bennett DA (2007), Conscientiousness and the incidence of Alzheimer disease and mild cognitive impairment, Archives of General Psychiatry, Vol. 64(10), pp. 1204-12

Zlatar Z.Z., Moore, R.C., Palmer B.W., Thompson W.K. and Jeste D.V. (2014) Cognitive complaints correlate with depression rather than concurrent objective cognitive impairment in the successful aging evaluation baseline sample., Journal of Geriatric Psychiatry and Neurology, Vol. 27(3), pp. 181-7. 


\section{Appendix A}

\section{A.1 Detailed descriptives and 'balancing tests'}

Table A.1 summarizes observed characteristics for the full sample and sub-samples by volunteering status. It is easy to see that volunteers and non-volunteers differ significantly from each other in almost all observable characteristics.

Table A.2 Panel A shows that significant observed differences between volunteers and non volunteers persist even after first differences. For illustration, two extreme cases are considered - individuals who completely stop volunteering (Panel A, column 1) and those who start volunteering (Panel A, column 2). Results are qualitatively similar for changes in volunteering at other levels as well. Table A.2 Panel B compares observed characteristics between respondents with spousal limitations and those without. The IV spousal limitations, is not predictive of changes in observed characteristics - the two subsamples are balanced ${ }^{17}$.

\section{Appendix B}

\section{B.1 Other determinants of cognitive ability}

Table B.1. presents the full set of OLS, FE and FE-IV estimates for the impact of volunteering on total cognitive ability. As expected, results show that cognitive function declines with age, retirement, worsening of health and loss of a spouse.

Table B.2. explores further how the impact of volunteering on cognitive ability would differ based on the respondents own physical and mental health status and employment. Table B.2 column (1) presents the FE-IV estimates of the impact of volunteering on cognitive ability without controls for physical or mental health and retirement status of the respondent. Column (2) includês controls for physical health and column (3) additionally controls for depression as well. Finally, to facilitate comparison, Table B.2 column (4) reproduces the FE-IV estimates of the impact of volunteering on cognitive ability from our main specification which includes the full set of controls for the respondent's employment status and, physical and mental health. Estimates in Appendix Table B.2 suggest that volunteering is consistently significantly protective of cognitive ability, with only small variations in effect sizes based on the physical health and retirement status of the respondent.

\footnotetext{
${ }^{17}$ For sake of completeness, observables of individuals with no changes in spousal limitations are also compared to those of individuals with increasing or decreasing spousal limitations. No significant differences were found in these paired comparisons either (McClellan (1994)).
} 
Table A.1: Summary Statistics of full sample, non-volunteers and volunteers in the Health and Retirement Study (1998-2010).

\begin{tabular}{|c|c|c|c|}
\hline & All & Non Volunteers & Volunteers \\
\hline HRS sample size & 64166 & 27999 & 36167 \\
\hline \multirow[t]{2}{*}{ Hours of volunteering past 12 months } & 87.44 & - & $135.68^{*}$ \\
\hline & $(131.33)$ & - & $(174.40)$ \\
\hline \multirow[t]{2}{*}{ TICS scores } & 22.91 & 21.36 & $23.77^{*}$ \\
\hline & $(4.78)$ & $(8.56)$ & $(5.46)$ \\
\hline \multirow[t]{2}{*}{ Crystallized intelligence } & 15.49 & 14.09 & $16.17^{*}$ \\
\hline & $(4.37)$ & $(7.61)$ & \\
\hline \multirow[t]{2}{*}{ Fluid intelligence } & 7.42 & 7.27 & $7.60^{*}$ \\
\hline & $(0.86)$ & $(1.75)$ & $(0.91)$ \\
\hline \multicolumn{4}{|c|}{ Socioeconomic and Demographic Characteristics } \\
\hline Females & 0.52 & 0.57 & $0.50^{*}$ \\
\hline Race White & 0.88 & 0.84 & $0.90^{*}$ \\
\hline Race Black & 0.10 & 0.13 & $0.08^{*}$ \\
\hline Race Other & 0.02 & 0.03 & $0.02 *$ \\
\hline \multirow[t]{2}{*}{ Mean Age (years) } & 70.38 & 70.76 & $70.16^{*}$ \\
\hline & $(4.40)$ & $(7.73)$ & $(5.31)^{*}$ \\
\hline \multirow[t]{2}{*}{ Mean household income } & 58905.07 & 49885.25 & $63880.74^{*}$ \\
\hline & $(452706.74)$ & $(1240871.05)$ & $(157413.72)^{*}$ \\
\hline Religion important & 0.67 & 0.63 & $0.69^{*}$ \\
\hline Education $\geq$ high school & 0.40 & 0.28 & $0.47^{*}$ \\
\hline Single & 0.31 & 0.34 & $0.25^{*}$ \\
\hline \multirow[t]{3}{*}{ Mean number of children } & 3.36 & 3.49 & $3.29 *$ \\
\hline & $(2.21)$ & $(3.94)$ & $(2.65)$ \\
\hline & 0.69 & 0.64 & $0.71^{*}$ \\
\hline \multicolumn{4}{|l|}{ Lifestyle factors } \\
\hline Smoke now & 0.12 & 0.16 & $0.09^{*}$ \\
\hline Smoke quit & 0.50 & 0.50 & 0.49 \\
\hline Consumes alcohol & 0.51 & 0.41 & $0.57^{*}$ \\
\hline \multicolumn{4}{|l|}{ Health Conditions } \\
\hline Underweight BMI $\left(<18.5 \mathrm{~kg} / \mathrm{m}^{2}\right)$ & 0.01 & 0.02 & $0.01^{*}$ \\
\hline Normal BMI $\left(18.5-24.9 \mathrm{~kg} / \mathrm{m}^{2}\right)$ & 0.29 & 0.29 & 0.29 \\
\hline Overweight BMI $\left(25-29.9 \mathrm{~kg} / \mathrm{m}^{2}\right)$ & 0.40 & 0.37 & $0.42^{*}$ \\
\hline Obese BMI $\left(>30 \mathrm{~kg} / \mathrm{m}^{2}\right)$ & 0.30 & 0.33 & $0.28^{*}$ \\
\hline ADL limitations & 0.13 & 0.22 & $0.08^{*}$ \\
\hline IADL limitations & 0.05 & 0.09 & $0.03^{*}$ \\
\hline Mobility limitations & 0.48 & 0.60 & $0.42^{*}$ \\
\hline High blood pressure & 0.59 & 0.64 & $0.56^{*}$ \\
\hline Heart ailment & 0.28 & 0.31 & $0.26^{*}$ \\
\hline Diabetes & 0.22 & 0.27 & $0.19^{*}$ \\
\hline Stroke & 0.06 & 0.09 & $0.05^{*}$ \\
\hline Depression & 0.12 & 0.19 & $0.09 *$ \\
\hline Arthritis & 0.66 & 0.67 & $0.65^{*}$ \\
\hline Chronic lung disease & 0.12 & 0.16 & $0.10^{*}$ \\
\hline Cancer & 0.17 & 0.18 & 0.17 \\
\hline
\end{tabular}

NOTES:

(1) * Significantly different between non-volunte 2 and volunteers at $p \leq 0.05$

(2) Standard deviation in parenthesis. 
Table A.2: Change in descriptive characteristics proportions and means (standard errors) by changes in volunteering status and spousal activity limitations (first out of three parts of the table)

PANEL A

PANEL B

\begin{tabular}{|c|c|c|c|c|}
\hline & $\begin{array}{c}\text { Stopped } \\
\text { vol. }\end{array}$ & $\begin{array}{c}\text { Started } \\
\text { vol. }\end{array}$ & $\begin{array}{c}\text { Fewer } \\
\text { spousal limits. }\end{array}$ & $\begin{array}{c}\text { More } \\
\text { spousal limits. }\end{array}$ \\
\hline \multicolumn{5}{|c|}{ Socioeconomic and Demographic characteristics } \\
\hline Mean age (years ) & 2.09 & $2.07^{*}$ & 2.09 & 2.10 \\
\hline Mean household income & -531.60 & -1827.99 & -2927.63 & -875.87 \\
\hline \multicolumn{5}{|c|}{ Marital status (ref. no change) } \\
\hline No change & .95 & .95 & .91 & $.98^{*}$ \\
\hline Became single & .04 & .04 & .09 & - \\
\hline Got married & .01 & $.01^{*}$ & & .02 \\
\hline \multicolumn{5}{|l|}{ Children (ref. no change) } \\
\hline No change & .94 & .94 & .96 & .95 \\
\hline Had child & .02 & .02 & .02 & .03 \\
\hline Lost child & .04 & .04 & .02 & .02 \\
\hline \multicolumn{5}{|l|}{ Retired (ref. no change) } \\
\hline No change & .81 & $.79^{*}$ & .81 & .81 \\
\hline Got retired & .11 & $14^{*}$ & .12 & .13 \\
\hline Came out of retirement & .07 & .07 & .07 & .06 \\
\hline \multicolumn{5}{|l|}{ Lifestyle factors } \\
\hline \multicolumn{5}{|l|}{ Smoke now (ref. no change) } \\
\hline No change & & $.97^{*}$ & .97 & .97 \\
\hline Started smoking & & .01 & .01 & .01 \\
\hline Quit smoking & .03 & .02 & .02 & .02 \\
\hline \multicolumn{5}{|c|}{ Consume alcohol (ref. no change) } \\
\hline No change & .85 & .84 & .85 & .86 \\
\hline Started drinking alcohol & .06 & $.09^{*}$ & .07 & .07 \\
\hline Quit drinking alcohol & .09 & $.07^{*}$ & .08 & .07 \\
\hline \multicolumn{5}{|c|}{ Health conditions } \\
\hline \multicolumn{5}{|c|}{ Underweight $\left(\mathrm{BMI}<18.5 \mathrm{~kg} / \mathrm{m}^{2}\right)$ (ref. no change) } \\
\hline No change & .99 & $.99^{*}$ & 1.00 & .99 \\
\hline Became underweight & .01 & $.01^{*}$ & .00 & .01 \\
\hline No longer underweight & .00 & .00 & .00 & .00 \\
\hline \multicolumn{5}{|c|}{ Normal BMI (18.5-24.9 kg/m²) (ref. no change) } \\
\hline No change & .89 & $.91^{*}$ & .92 & .91 \\
\hline Became normal BMI & .05 & $.04^{*}$ & .04 & .05 \\
\hline No longer normal BMI & .06 & .05 & .04 & .04 \\
\hline
\end{tabular}

NOTES:

(1)* Statistically different between non-volunteers and volunteers at $p \leq 0.05$

(2) Standard deviation in parenthesis. 
Table A.2: (continued; second out of three parts)

PANEL A

PANEL B

\begin{tabular}{|c|c|c|c|c|}
\hline & Stopped vol. & Started vol & Fewer SADL & More SADL \\
\hline \multicolumn{5}{|c|}{ Overweight (BMI $25-29.9 \mathrm{~kg} / \mathrm{m}^{2}$ ) (ref. no change) } \\
\hline No change & .82 & .82 & .86 & .83 \\
\hline Became overweight & .09 & .09 & .08 & .08 \\
\hline No longer overweight & .09 & .09 & .06 & $.09^{*}$ \\
\hline \multicolumn{5}{|c|}{ Obese $\left(\mathrm{BMI} \geq 30 \mathrm{~kg} / \mathrm{m}^{2}\right)$ (ref. no change) } \\
\hline No change & .91 & .90 & .92 & .91 \\
\hline Became obese & .04 & $.06^{*}$ & .03 & $.05^{*}$ \\
\hline No longer obese & .05 & .04 & .05 & .04 \\
\hline \multicolumn{5}{|l|}{ Own ADL limitations (ref. no change) } \\
\hline No change & .82 & $.87^{*}$ & .88 & .88 \\
\hline Developed ADL limitations & .11 & $.07^{*}$ & .07 & .08 \\
\hline No longer ADL limitations & .07 & .06 & .05 & .04 \\
\hline \multicolumn{5}{|l|}{ Own IADL limitations (ref. no change) } \\
\hline No change & .92 & $.93^{*}$ & .95 & .94 \\
\hline Developed IADL limitations & .05 & $.04^{*}$ & .03 & .04 \\
\hline No longer IADL limitations & .03 & .03 & .02 & .02 \\
\hline \multicolumn{5}{|c|}{ Own mobility limitations (ref. no change) } \\
\hline No change & .53 & $.58^{*}$ & .62 & .62 \\
\hline Developed mob. limits. & .30 & $.23^{*}$ & .21 & .22 \\
\hline No longer mob. limits. & .17 & .19 & .17 & .16 \\
\hline \multicolumn{5}{|l|}{ High blood pressure (ref. no change) } \\
\hline No change & .95 & .95 & .95 & .95 \\
\hline Developed high blood pressure & .05 & .05 & .05 & .05 \\
\hline No longer high blood pressure & - & - & - & - \\
\hline \multicolumn{5}{|l|}{ Heart ailment (ref. no change) } \\
\hline No change & .94 & $.95^{*}$ & .95 & .94 \\
\hline Developed heart ailment & .05 & $.04^{*}$ & .04 & .05 \\
\hline No longer heart ailment & .01 & $.01^{*}$ & .01 & .01 \\
\hline \multicolumn{5}{|l|}{ Diabetes (ref. no change) } \\
\hline No change & .95 & .96 & .96 & .96 \\
\hline Developed diabetes & .04 & .03 & .04 & .03 \\
\hline No longer diabetes & .01 & .01 & .00 & .01 \\
\hline \multicolumn{5}{|l|}{ Stroke (ref. no change) } \\
\hline No change & .98 & .98 & .99 & .99 \\
\hline Had & .02 & .02 & .01 & .01 \\
\hline
\end{tabular}

(1)* Statistically different between non-volunteers and volunteers at $p \leq 0.05$

(2) Standard deviation in parenthesis. 
Table A.2: (continued; third out of three parts)

PANEL A

PANEL B

\begin{tabular}{|c|c|c|c|c|}
\hline \multirow{2}{*}{ Depression (ref. no change) } & \multirow[t]{2}{*}{ Stopped vol. } & \multicolumn{2}{|c|}{ Started vol Fewer SADL } & \multirow[t]{2}{*}{ More SADL } \\
\hline & & & & \\
\hline No change & .85 & & .88 & .90 \\
\hline Developed depression & .08 & .07 & .06 & .05 \\
\hline No longer depression & .07 & .08 & .06 & .05 \\
\hline Arthritis (ref. no change) & & & & \\
\hline No change & .94 & .93 & .93 & .93 \\
\hline Developed arthritis & .04 & .05 & .05 & .06 \\
\hline No longer arthritis & .02 & .02 & .02 & .01 \\
\hline Chronic lung disease (ref. no chang & & & & \\
\hline No change & .97 & .97 & .97 & .98 \\
\hline Developed chronic lung disease & .02 & .02 & .02 & .02 \\
\hline No longer chronic lung disease & .01 & .01 & .01 & .00 \\
\hline Cancer (ref. no change) & & & & \\
\hline No change & .97 & .96 & .97 & .97 \\
\hline Got cancer & .03 & .03 & .03 & .03 \\
\hline No longer cancer & .00 & .01 & .00 & .00 \\
\hline$N$ & 12,075 & 9,392 & 4,493 & 5,352 \\
\hline
\end{tabular}

(1)* Statistically different between non-volunteers and volunteers at $p \leq 0.05$

(2) Standard deviation in parenthesis. 
Table B.1: OLS, Individual Fixed Effects (FE) and Fixed Effects - Instrumental Variable (FE-IV) estimates of the impact of volunteering on individual cognitive ability.

\begin{tabular}{|c|c|c|c|c|c|c|}
\hline \multirow{2}{*}{ Volunteering } & \multicolumn{2}{|c|}{$\begin{array}{c}(1) \\
\text { OLS }\end{array}$} & \multicolumn{2}{|c|}{$\begin{array}{l}(2) \\
\mathrm{FE}\end{array}$} & \multicolumn{2}{|c|}{$\begin{array}{c}\text { (3) } \\
\text { FE-IV }\end{array}$} \\
\hline & $0.0044^{*}$ & $(0.00)$ & $0.0014^{*}$ & $(0.00)$ & $0.013^{*}$ & $(0.01)$ \\
\hline Business cycle at birth & $-0.73^{*}$ & $(0.23)$ & 0 & (.) & 0 & $()$. \\
\hline Household income & 0.00 & $(0.00)$ & -0.00 & $(0.00)$ & -0.00 & $(0.00)$ \\
\hline Edu $\geq$ high school & $2.10^{*}$ & $(0.05)$ & 0 & (.) & 0 & \\
\hline \multicolumn{7}{|c|}{ Age in years (reference ' $\leq 65$ years') } \\
\hline $65-69$ & $-0.76^{*}$ & $(0.07)$ & $-0.76^{*}$ & $(0.12)$ & $-0.65^{*}$ & $(0.14)$ \\
\hline $70-74$ & $-1.50^{*}$ & $(0.08)$ & $-1.60^{*}$ & $(0.12)$ & $-1.39^{*}$ & $(0.17)$ \\
\hline $75-79$ & $-2.30^{*}$ & $(0.09)$ & $-2.57^{*}$ & $(0.13)$ & $-2.18^{*}$ & $(0.24)$ \\
\hline $80-84$ & $-3.42^{*}$ & $(0.10)$ & $-3.88^{*}$ & $(0.15)$ & $-3.25^{*}$ & $(0.36)$ \\
\hline $85+$ & $-5.04^{*}$ & $(0.12)$ & $-5.93^{*}$ & $(0.17)$ & $-5.04^{*}$ & $(0.49)$ \\
\hline Female & $1.07^{*}$ & $(0.06)$ & 0 & (.) & 0 & (.) \\
\hline \multicolumn{7}{|l|}{ Race (reference 'White') } \\
\hline Black & $-2.94^{*}$ & $(0.09)$ & & (.) & 0 & (.) \\
\hline Other & $-1.93^{*}$ & $(0.18)$ & 0 & $()$. & 0 & $()$. \\
\hline Retired & 0.084 & $(0.05)$ & $-0.16^{*}$ & $(0.05)$ & $-0.24^{*}$ & $(0.06)$ \\
\hline Religion very important & $-0.25^{*}$ & $(0.05)$ & 0.030 & $(0.06)$ & -0.0067 & $(0.06)$ \\
\hline \multicolumn{7}{|c|}{ Smoking status (reference 'Never smoked regularly') } \\
\hline Current smoker & $-0.28^{*}$ & $(0.09)$ & -2.00 & $(1.74)$ & -1.23 & $(1.69)$ \\
\hline Past smoker & -0.030 & $(0.06)$ & -2.31 & $(1.75)$ & -1.56 & $(1.69)$ \\
\hline Drinks alcohol & $0.85^{*}$ & $(0.05)$ & $0.18^{*}$ & $(0.05)$ & 0.12 & $(0.06)$ \\
\hline \multicolumn{7}{|c|}{ BMI (reference 'Underweight $B M I<18.5 \mathrm{~kg} / \mathrm{m}^{2}$ ') } \\
\hline Normal $\left(18.5-24.9 \mathrm{~kg} / \mathrm{m}^{2}\right)$ & $0.58^{*}$ & $(0.16)$ & $0.72^{*}$ & $(0.17)$ & $0.64^{*}$ & $(0.18)$ \\
\hline Overweight $\left(25-29.9 \mathrm{~kg} / \mathrm{m}^{2}\right)$ & $0.82^{*}$ & $(0.17)$ & $0.99^{*}$ & $(0.18)$ & $0.83^{*}$ & $(0.20)$ \\
\hline Obese $\left(\geq 30 \mathrm{~kg} / \mathrm{m}^{2}\right)$ & $0.96^{*}$ & $(0.17)$ & $1.28^{*}$ & $(0.19)$ & $1.10^{*}$ & $(0.21)$ \\
\hline Have ADL limits. & $-0.77^{*}$ & $(0.06)$ & $-0.53^{*}$ & $(0.05)$ & $-0.44^{*}$ & $(0.08)$ \\
\hline Have IADL limits. & $-3.00^{*}$ & $(0.09)$ & $-1.43^{*}$ & $(0.08)$ & $-1.35^{*}$ & $(0.09)$ \\
\hline Have mobility limits. & $-0.20^{*}$ & $(0.05)$ & $-0.17^{*}$ & $(0.04)$ & -0.085 & $(0.06)$ \\
\hline Depression & $-1.25^{*}$ & $(0.06)$ & $-0.19^{*}$ & $(0.05)$ & $-0.17^{*}$ & $(0.06)$ \\
\hline High blood pressure & $-0.16^{*}$ & $(0.05)$ & $-0.35^{*}$ & $(0.07)$ & $-0.29^{*}$ & $(0.08)$ \\
\hline Stroke & $-0.81^{*}$ & $(0.10)$ & $-1.07^{*}$ & $(0.13)$ & $-0.91^{*}$ & $(0.15)$ \\
\hline Arthritis & $0.14^{*}$ & $(0.05)$ & 0.086 & $(0.07)$ & 0.076 & $(0.07)$ \\
\hline Chronic lung disease & $0.26^{*}$ & $(0.08)$ & 0.069 & $(0.09)$ & 0.18 & $(0.12)$ \\
\hline Cancer & $0.36^{*}$ & $(0.07)$ & -0.057 & $(0.09)$ & 0.14 & $(0.14)$ \\
\hline Diabetes & $-0.45^{*}$ & $(0.07)$ & -0.045 & $(0.08)$ & -0.029 & $(0.09)$ \\
\hline Heart ailment & 0.047 & $(0.06)$ & $-0.27^{*}$ & $(0.07)$ & $-0.20^{*}$ & $(0.08)$ \\
\hline Single & $-0.22^{*}$ & $(0.06)$ & $-0.21^{*}$ & $(0.07)$ & $-0.31^{*}$ & $(0.09)$ \\
\hline Number children & $-0.073^{*}$ & $(0.01)$ & -0.049 & $(0.03)$ & -0.059 & $(0.03)$ \\
\hline $\mathrm{N}$ & 64161 & & 64161 & & 55696 & \\
\hline
\end{tabular}

NOTES:

(1) Standard errors in parenthesis; * $p \leq 0.05$

(2) Additional controls, not shown, include dummies for missing values. 
Table B.2: Mediation analysis of impact of volunteering (formal+informal) on individual total cognitive ability. Fixed effect-instrumental variable specification.

\begin{tabular}{lcccc}
\hline & $(1)$ & $(2)$ & $(3)$ & $(4)$ \\
\hline Vol. & $0.017^{*}$ & $0.016^{*}$ & $0.013^{*}$ & $0.013^{*}$ \\
& $(0.01)$ & $(0.01)$ & $(0.01)$ & $(0.01)$ \\
Retired & No & Yes & Yes & Yes \\
Physical Health $\dagger$ & No & No & Yes & Yes \\
Depression $\ddagger$ & No & No & No & Yes \\
First stage F-stat. & 14.11 & 14.21 & 13.25 & 13.27 \\
\hline $\mathrm{N}$ & 55696 & 55696 & 55696 & 55696 \\
\hline \hline
\end{tabular}

NOTES:

(1) Standard errors in parenthesis; ${ }^{*} p \leq 0.05$

(2) $\dagger$ Controls for physical health included are individual indicators for underweight, overweight or obese, activities of daily living limitations, instrumental activities of daily living limitations or mobility limitations, hypertension, any other heart ailment, diabetes, arthritis, chronic lung disease, cancer and stroke.

(3) $\ddagger$ Respondent's CESD depression score.

\section{Appendix C}

\section{C.1 Measurement error in volunteering}

Measurement error (ME) may bias the estimates of the causal effect of volunteering on cognitive decline. If the ME is time constant, fixed effects in FE-IV model would provide consistent estimates of the effect of changes in volunteering on cognitive decline. In case of time varying endogenous $\mathrm{ME}$, as long as it is uncorrelated to the instrument (IV), onset of daily living limitations of spouses, our estimates would remain consistent. An example of time varying ME may be, if the cognitively impaired consistently over report volunteering activity to earn more socially desirability. Then, $V_{o l}^{\text {Reported }}=V o l^{\text {Actual }}+M E$ with $\mathrm{ME} \geq 0$ and increasing with cognitive decline. As long as spousal limitations is uncorrelated with individual cognitive decline, established in Section 3 in the main text, the FE-IV results will be consistent even in the presence of ME in self reported volunteering. Descriptively, if cognitively impaired individuals report higher $\mathrm{Vol}^{\text {Reported }}$, i.e. have larger ME, we should observe an inverse relationship between cognitive function and volunteering. But, in fact, we find the opposite with more volunteering by respondents with higher cognitive levels. Thus, the results are a lower bound of the potential favorable impact of volunteering on cognitive ability in presence of ME. In absence of ME the estimates could be even larger.

\section{C.2 Selective attrition over time}

If the same cohort is followed over time, individuals with the worst cognitive ability would attrit out of the panel. The resulting panel would be younger, with better cognitive ability 
and possibly higher volunteering levels due to better over all health. Not controlling for selective panel attrition would then lead to a spurious significant positive relationship between volunteering and cognitive ability.

Presence of any selective panel attrition is first investigated descriptively by considering the pattern of mean age, volunteering participation and TICS cognition scores by HRS wave. Table B.1. shows that the mean age of the sample is significantly different in each wave but the change is non-monotonic over time. Even though each wave is approximately two years apart the mean age is not consistently increasing by about two years. This is in part due to the evolution of the sampling design of the HRS. The 1998 wave, the first used in this study, is cross-sectionally representative of the US population older than 50. Since then steady state has been maintained by adding a new six-year cohort every six years (Willis, 1999). For instance, in 2004, a fresh screening sample of 'Early Boomers' born in 1948-1953, who were between 51 to 56 years old at the time was added. This generated a random sample of younger cohorts in the subsequent waves of the HRS and explains the visibly larger sample size in 2004, which is also associated to a lower mean age and higher cognitive score in wave 4. Unlike mean age, it is worth mentioning that mean volunteering hours and cognitive scores are not statistically significantly different across the waves (refer Table B.1.).

Table C1: Age, hours of volunteering in past 12 months and cognitive score, by wave of HRS.

\begin{tabular}{l|l|c|c|c|c|c|c|cc}
\hline \multicolumn{1}{l|}{ Wave } \\
\hline \multirow{2}{*}{ Year } & & 1 & 2 & 3 & 4 & 5 & 6 & 7 & \\
\hline Age & & 1998 & 2000 & 2002 & 2004 & 2006 & 2008 & 2010 & Total \\
\hline \multirow{3}{*}{ Hours of Vol. } & Mean & 69.78 & 74.38 & 74.42 & 68.60 & 74.06 & 74.46 & 75.03 & 72.68 \\
(past 12 mths.) & S.D. & 11.64 & 7.65 & 7.52 & 12.10 & 7.86 & 7.89 & 7.62 & 10.13 \\
Cognitive score (0-35) & Mean & 84.46 & 77.05 & 65.60 & 80.27 & 75.87 & 73.21 & 75.04 & 76.45 \\
& S.D. & 15.95 & 11.71 & 10.37 & 13.19 & 9.43 & 9.15 & 9.30 & 4.86 \\
Total N & Mean & 22.06 & 21.40 & 21.50 & 22.18 & 21.64 & 21.79 & 21.28 & 21.73 \\
& S.D. & 0.70 & 0.46 & 0.45 & 0.61 & 0.39 & 0.39 & 0.38 & 0.20 \\
& & 9409 & 7233 & 6978 & 12103 & 9652 & 9716 & 9075 & 64166 \\
\hline
\end{tabular}

A formal check for any selective attrition bias is done by weighting the observations in the FE-IV model with the inverse of their estimated attrition probability. We follow the method proposed by Becketti, Gould, Lillard and Welch (1988) that gives more weight to observations that have the same initial characteristics to those that attrit than to those with characteristics that make them more likely to remain in the panel. ${ }^{18}$ Results presented in

\footnotetext{
${ }^{18}$ Specifically, we estimate the unrestricted probit model $A=x_{i 1} \gamma+a_{i 1} \delta+v_{i}$ where $A$ is a dummy that takes a value of 1 if the respondent is not in the panel for at least two waves. $x_{i 1}$ is a vector of auxiliary variables which can be related to both attrition and cognitive health and includes indicator for economic conditions at time of birth, age, dummy for retirement, smoking status, dummy for whether respondent consumes alcohol or not, controls for BMI and dummies for various health conditions. $a_{i 1}$ includes other controls like gender, race, education, income, and importance of religion. Next, we estimate a restricted version of the equation without the auxiliary variables, $A=x_{i 1} \gamma+\varphi_{i}$. The ratio of the predicted probabilities from the restricted and the unrestricted model, $W_{i}=\frac{p^{r}}{p^{u}}$, gives the inverse probability weights.
} 
Table B.2. show that regression estimates for the impact of volunteering on cognitive ability are qualitatively similar with or without attrition weights. 


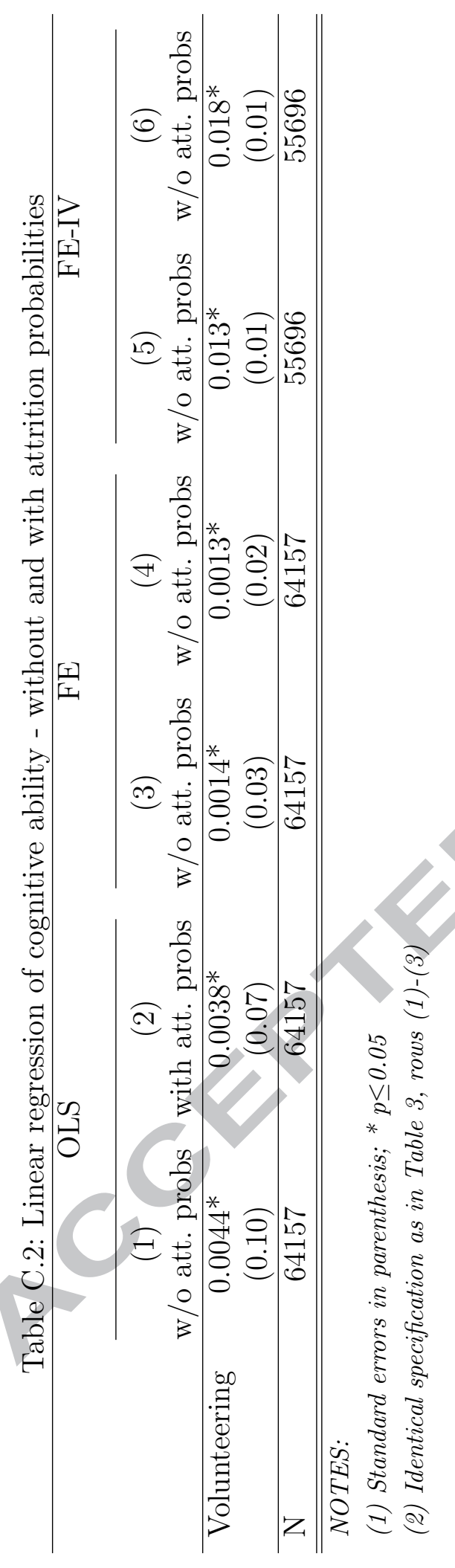




\section{C.3 Accounting for missing values}

The sample used for all the analysis is restricted to include observations for whom the dependent variable of TICS cognitive score and the main explanatory variable, hours of volunteering, are non-missing. Almost all other controls in the regressions are coded as categorical variables. Consequently missing values, if any, are accounted for simply by an indicator which takes a value of one in case of a missing, 0 otherwise. This is the traditional method of coding missing values and helps retain observations that may be otherwise lost due to one missing explanatory variable value. More recently, multiple imputations to recode missing values has been proposed as a preferred method since it accounts for the possibility of non-random missing values. Also, each imputation can account for whether the variable is continuous, categorical, ordered etc and use the appropriate imputation model. For instance, since individual ADLs range from 0-3 we used ordered probit to impute any missing values while logit was used to impute missings for the binary diabetes indicator for the respondent. We tested for the sensitivity of the results to these alternative methods of recoding missing values. Results presented in Table B.3. show that the results are robust to the alternative specifications.

Table C.3: FE-IV impact of volunteering on cognitive ability - dummy versus multiple imputation of missing values.

$(1) \quad(2)$

Dummy for missing Multiple imputation

\begin{tabular}{lllll}
\hline Volunteering & $0.013^{*}$ & $(0.01)$ & $0.014^{*}$ & $(0.01)$ \\
\hline $\mathrm{N}$ & 55696 & & 53047 & \\
\hline \hline NOTES: & & &
\end{tabular}

(1) Standard errors in parenthesis; * $p \leq 0.05$

(2) Identical specification as in Table 3, rows (1)-(3)

\section{Appendix D}

\section{D.1 Depression mediating protective effect of volunteering against cognitive decline}




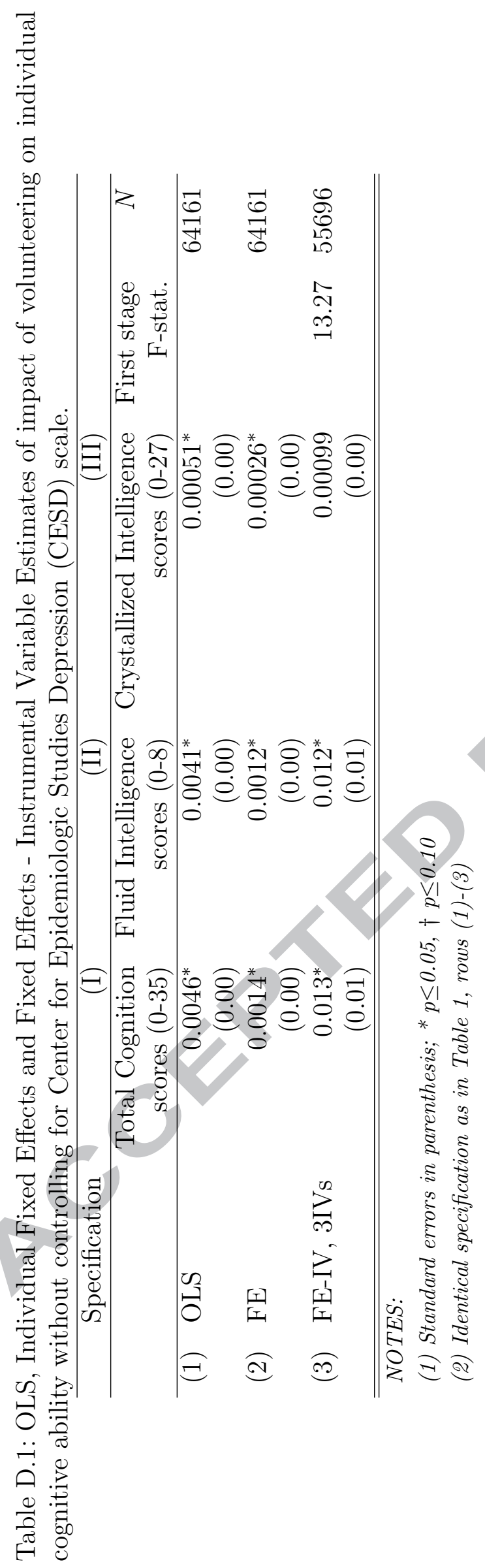




\section{Appendix E}

\section{E.1 Savings in cost of dementia due to volunteering}

Quantifying the monetary cost of cognitive decline is challenging. Some cognitive decline is a natural aspect of aging and may result in mild loss of memory and executive function, with limited associated costs to the individual. Rapid cognitive decline, however, may lead to Mild Cognitive Impairment (MCI), or worse, dementia that can significantly hinder independent functioning of the individual. Cognitive decline, depending on the extent, is associated to large care-giving and health care costs and loss of income and wealth due to suboptimal decision making. Total costs owing to cognitive decline are hard to quantify due to a significant non-market component, for instance care giving by friends and family.

Hurd et. al, 2013 have used the HRS to estimate the total health care cost of dementia as the sum of purchased care for dementia patients and a valuation of the informal (unpaid) care provided by friends and family. The main HRS lacks clinical assessments for dementia. However, a subset of 856 respondents from the HRS participated in the nationally representative Aging, Demographics and Memory Study (ADAMS) and were assessed by a physician for dementia. The authors then estimated an ordered probit model with three potential outcomes - normal, cognitive impairment but not dementia (CIND) and demented for the ADAMS subsample ${ }^{19}$. Out of the 285 cases ADAMS clinically classified as demented, the probability model of Hurd et. al (2013) correctly classified 222 as demented as well for a sensitivity of $77.9 \%$. Table C.1. column (1) presents the estimates of the predictors of dementia from Hurd et. al (2013). Column (2), Table C.1. presents our replication of the Hurd et. al (2013) model. Our re-estimates correctly classified 237 out of 308 clinical cases of dementia for a slightly lower sensitivity of $76.9 \%$. Of the 541 cases with the clinical ADAMS classification of non-demented, Hurd et. al (2013) correctly identify 486 as non-demented for a specificity of $89.8 \%$. Our re-estimation provides a similarly high specificity of $88.9 \%$ by correctly classifying 487 out of 548 non-demented cases. Comparing estimates from Columns (1) and (2) of Table C.1. I am assured that my replication of the Hurd et. al (2013) model is reasonably accurate. Next, I extend the model to include volunteering as an additional predictor of dementia. Results from this extension are presented in Table C.1, column (3). The extended model predicts 14 fewer cases, i.e. a $5.9 \%$ decline in the predicted incidence of dementia. A simple likelihood ratio test comparing the smaller Hurd et. al (2013) model with my extended model with volunteering as a predictor of dementia rejects the smaller model at the $1 \%$ level of significance with a test statistic of 9.36 and a $\chi^{2}(1)$ critical value of 6.64 .

Finally, I compare health care costs - self reported out-of-pocket spending, nursing home

\footnotetext{
${ }^{19}$ Please refer to the Supplementary Appendix of Hurd. et al (2013) available at NEJM.org for details of the method of estimation of dementia status.
} 
Table E.1: Probability model predicting dementia in Aging, Demographics and Memory Study (ADAMS) sample.

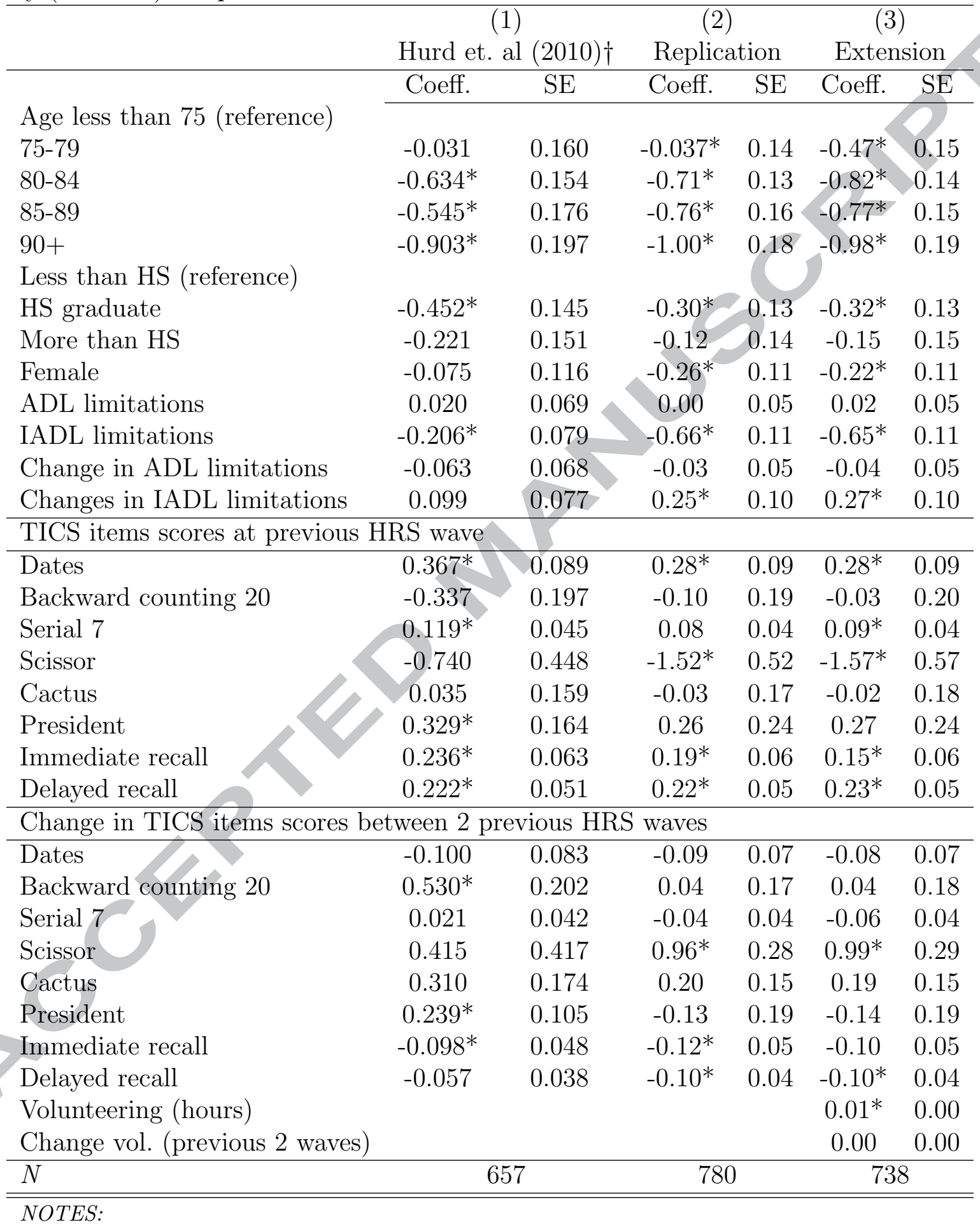

(1) ${ }^{\dagger}$ Reproduced from Table S2 of the Supplementary Appendix of Hurd et. al (2013).

(2) * $p \leq 0.05$ 
care and Medicare claims - associated to dementia from Hurd et. al (2013) and my extended model. I assume that the predicted reduction in incidence of dementia from volunteering results in an equal savings in dementia related health care costs. Depending on the method used to impute the informal component of the care-giving cost to dementia patients, Hurd et. al (2013), estimate the total monetary cost of dementia in 2010 to be between $\$ 157$ $\$ 215$ billion, of which $\$ 11$ billion was paid by Medicare. A $5.9 \%$ reduction in costs due to volunteering would then amount to savings of $\$ 9.26-\$ 15.16$ billion in 2010 dollars. This is likely to be a lower bound of the health care savings associated to volunteering as it does not account for health care savings for patients with cognitive impairment but not dementia (CIND) and also does not take into account the monetary value of the positive externalities that volunteers will generate. 